\title{
Gender-Related Immune-Inflammatory Factors, Age-Related Diseases, and Longevity
}

\author{
Giuseppina Candore, Carmela Rita Balistreri, Giuseppina Colonna-Romano, \\ Domenico Lio, Florinda Listì, Sonya Vasto, and Calogero Caruso
}

\begin{abstract}
This review discusses the role of estrogens as pro- or antiinflammatory players in immune-inflammatory responses. In particular, their role in Alzheimer's disease (AD), an example of immune-inflammatory disease, is discussed briefly. AD is a progressive neurodegenerative disease, which in Western societies accounts for the majority of cases of clinical senile dementia. However, sexual dimorphism of diseases may also depend on factors independent of sex hormones (i.e., a gender effect), as demonstrated by our data on differential longevity in females and males. In fact, differences in mortality between men and women are not only a question of sex that refers to biological differences, but rather a question of "socially constructed sex," a question of gender (i.e., the characteristics that a society or culture delineates as masculine or feminine). In gender medicine, we conclude that it is important to consider the role played both by hormones, customs, and educational levels regarding the different propensity of males and females to fall ill. So, in programming antiaging strategies, we have also to take these aspects into account.
\end{abstract}

\section{Role of Estrogens in Immune and Inflammatory Response}

$\mathbf{T}$ HE SEVERITY OF INFLAMMATORY DISEASES (e.g., atherosclerosis, neurological disorders, periodontitis, and rheumatoid arthritis) is correlated with gender differences (e.g., level of female sex hormones), suggesting that female sex hormones modulate the inflammatory response. ${ }^{1}$ The three major estrogens in women are estradiol, estriol, and estrone. The main form of estrogen before menopause is estradiol. The steroid hormone $17 \beta$-estradiol (E2) is produced mainly by the ovaries and the placenta and is released into the bloodstream. ${ }^{2}$ In normally cycling adult women, the ovarian follicle secretes $70-500 \mu \mathrm{g}$ of estradiol per day, causing changes in plasma estrogen concentration from $210 \mathrm{pmol} / \mathrm{L}$ in the early follicular phase and $720 \mathrm{pmol} / \mathrm{L}$ in the late follicular phase, to $490 \mathrm{pmol} / \mathrm{L}$ in the late luteal phase. In menopausal women, ovarian production of E2 is significantly diminished and the plasma estrogen concentration is reduced to $<100 \mathrm{pmol} / \mathrm{L}^{3} \mathrm{E} 2$ mediates its action mainly through its intracellular receptors, ER- $\alpha$ and ER- $\beta$, which are the two major forms of estrogen receptor (ER) that belong to a large family of transcription factors, the nuclear receptor family. Apart from the two classical receptors, there is at least one other functional estrogen known as GPR30, which is expressed in various cancers and tumor line cells. ${ }^{4}$
Estrogen transmits its signal through different pathways. According to the classical mode of estrogen signaling, estrogens diffuse through cell membranes into the cytoplasm, bind to and dimerize their receptor $(\mathrm{ER}-\alpha$ or $\mathrm{ER}-\beta)$, and finally migrate into the nucleus where the estrogen-bound receptor binds to the estrogen response elements (ERE) of target genes and induces gene expression. Estrogen also mediates nongenomic effects through activation of signaling kinases. ${ }^{2,4}$ Estrogen receptors have been detected not only in classical reproductive tissue, but also in immune cell populations, including lymphocytes, monocytes, and macrophages, and even within brain glial cells. ${ }^{5}$

Evidence suggests that estrogens affect the immune system and the processes associated with inflammation. ${ }^{6}$ There is still an unresolved paradox with respect to the immunomodulating role of estrogens. E2 at periovulatory to pregnancy levels most often has antiinflammatory effects by inhibiting many proinflammatory pathways of innate immunity, adaptive immunity, and inflammatory tissue responses. ${ }^{7}$ Arguments in favor of a proinflammatory response are the antiapoptotic effects on immune cells, promotion of neoangiogenesis, and stimulation of $\mathrm{B}$ cells, which has been delineated to be an unfavorable factor in B cell-driven diseases such as systemic lupus erythematosus. If B cells are dominant in an inflammatory disease, estrogens at all levels stimulate the disease process. In chronic inflammatory

Immunesenescence Unit, Department of Pathobiology and Biomedical Methodology, University of Palermo, Italy. 
diseases, where monocytes, macrophages, dendritic cells, $\mathrm{T}$ cells, fibroblasts, and neutrophils play a dominant role, estrogens demonstrate a dual role: At low concentrations estrogens stimulate, and, at high levels, estrogens inhibit the disease process. $\mathrm{B}$ cells, $\mathrm{T}$ cells, and macrophages are decisive for the initiation of autoimmune diseases ${ }^{7}$. Hence, estrogens can have quite opposite roles depending on involved cells. If $B$ cells play a central role by antigen presentation, autoantibody production, and/or bystander cytokine secretion, E2 will probably speed up the outbreak of the disease in the early reproductive years. On the other hand, if T cells play an equal or more important role than $B$ cells, the onset of disease in a woman will be delayed because E2 inhibits T cell autoimmunity. In that situation, the onset of the disease might be shifted to the late reproductive phase or postmenopausal period.

Thus, the effects of estrogens are dependent on criteria such as: (1) the immune stimulus (foreign antigens or autoantigens) and subsequent antigen-specific immune responses (e.g., $\mathrm{T}$ cells inhibited by estrogens vs. activation of B cells); (2) the cell types involved during different phases of the disease; (3) the target organ with its specific microenvironment; (4) the concentration of estrogens; (5) the variability in expression of ER- $\alpha$ and ER- $\beta$, depending on the microenvironment and the cell type; and (6) intracellular metabolism of estrogens leading to important biologically active metabolites with quite different anti- and proinflammatory functions.

A uniform concept for the action of estrogens cannot be found for all known chronic inflammatory diseases. Nevertheless, for strictly B cell-dependent diseases, the female-tomale preponderance can be explained by the propagating effects of estrogens. The smaller the influence of B cells and the bigger the weight of $\mathrm{T}$ cells and other cells, the less evident is the sex dimorphism in chronic inflammatory diseases. ${ }^{7}$ Finally, sexual dimorphism of diseases may also depend on factors independent of sex hormones (i.e., a gender effect; see below).

\section{Alzheimer Disease: A Model of Inflammatory Disease and Estrogen Therapy}

Estrogens are thought to play a role in the sex difference observed in many neurological diseases with inflammatory components, including stroke, Alzheimer's and Parkinson's diseases, multiple sclerosis, or amyotrophic lateral sclerosis. ${ }^{5}$ Alzheimer's disease (AD) is a progressive neurodegenerative immune-inflammatory disease, which in Western societies accounts for the majority of cases of clinical senile dementia. ${ }^{8-10} \mathrm{AD}$ is characterized by global cognitive dysfunction, especially memory loss, behavior or personality changes, and impairments in the performance of activities of daily living. Neuropathological hallmarks of AD are neuritic plaques and neurofibrillary tangles. ${ }^{11,12}$ Neuritic plaques are extracellular deposits of the $\beta$-amyloid peptide (A $\beta)$; these plaques are usually in a milieu of reactive astrocytes, activated microglia, degenerating axons, and dendrites. ${ }^{13}$ Neurofibrillary tangles are intracellular deposits of hyperphosphorylated degenerate filaments, which result from aggregations of the microtubular protein tau, frequently conjugated with ubiquitin. ${ }^{11,13}$ As these cellular changes progress, brain atrophy and neuronal loss in the hippocampus, temporal cortex, and limbic area are observed. ${ }^{14}$
Age is the first and foremost risk factor in AD. The prevalence of $\mathrm{AD}$ is approximately $1 \%$ between age 65 and 69 and is higher than $60 \%$ in individuals over age $80-85 .{ }^{15}$ Although the mean age of $\mathrm{AD}$ onset is around 80, early-onset disease, defined arbitrarily as the illness occurring before the age of 60 , can occur, although it is rare. Thus, early-onset cases make up about $6-7 \%$ of all cases of AD. A significant number of earlyonset cases are inherited, with an autosomal dominant pattern of high penetrance. AD may not be an inevitable element of the aging process, but it is a disease with significant genetic roots. Genetics is important not only in predicting susceptibility, but also age of onset in the elderly. ${ }^{12,13,16}$ In most studies, women were found to be at greater risk for $\mathrm{AD}$ (a ratio of 1.2 to 1.5). This datum seems to be robust even after adjustment for the well-known differences in survival rates and, reciprocally, for education level. However, it is not clear if this effect is due to genetic or hormonal differences between males and females or it is a surrogate marker of other unmeasured socioeconomic factors. ${ }^{17-19}$

A possible factor influencing $\mathrm{AD}$ incidence in women is the loss of ovarian estrogen production after menopause. In fact, cumulative evidence from basic science and clinical research suggests that estrogens play a significant neuromodulatory and neuroprotective role in the brain, which underlies the ability of estrogens to ameliorate symptoms associated with Parkinson's disease and tardive dyskinesia ${ }^{20-22}$ and to decrease the incidence and delay the onset of AD. ${ }^{23-25}$ Subsets of neurons possess intraneuronal receptors for estrogen. ${ }^{26}$ The complex of estrogens and its receptor translocates into the cell nucleus, where it regulates transcription of target genes. Through interactions with membrane receptors, estrogens also influence neuronal functions in ways that do not require genomic interactions. ${ }^{27}$ A number of estrogen actions have the potential to affect $\mathrm{AD}$ incidence or $\mathrm{AD}$ symptoms. ${ }^{28}$ Estrogens, for example, are neuroprotective against a variety of experimental insults, including oxidative stress, excitatory neurotoxicity, and ischemia ${ }^{29,30}$; they can promote the growth of nerve processes and modulate synaptic plasticity. ${ }^{31,32}$ Other putatively benefical actions include increase of cerebral blood flow, enhancing glucose transport into the brain, and reductions in $\beta$-amyloid formation. ${ }^{33-35}$

The cessation of ovarian estrogen production in postmenopausal women might facilitate $\mathrm{A} \beta$ deposits by increasing the local concentrations of $\mathrm{A} \beta$ in the brain. In addition, $17 \beta$-estradiol treatment is associated with diminution of brain $\mathrm{A} \beta$ levels, suggesting that modulation of $\mathrm{A} \beta$ metabolism may be one of the ways by which estrogen replacement therapy might prevent or delay the onset of $\mathrm{AD}$ or both in postmenopausal women (see below) ${ }^{35}$. However, some estrogen actions might be harmful. Pro-inflammatory effects could be deleterious, ${ }^{36}$ and the prothrombotic properties of some estrogens could adversely affect the cerebral vasculature. $^{37}$

As mentioned above, oxidative stress and mitochondrial defects have also been implicated in the pathogenesis of $\mathrm{AD}^{38}$ The formation and resulting effects of both senile plaques and neurofibrillary tangles have been associated with oxidative stress. ${ }^{38}$ There are reciprocal actions between oxidative stress and both tau hyperphosphorylation and amyloid $\beta$ pathology. The interplay between the three actors in $\mathrm{AD}$ pathology converge on the mitochondria, resulting in disruption of the electron transport chain production of 
adenosine triphosphate (ATP), release of proapoptotic proteins, and substantial alterations in the cellular reductionoxidation (redox) potential of the cell, which in turn can feed back to increase the pathological load by further altering the tau, amyloid $\beta$, and reactive oxygen species (ROS) balance.

These findings, which provide evidence for interplay between neuronal oxidative stress and AD pathology, indicate a common point of action for protection against neurodegeneration. ${ }^{39}$ Estradiol reduces the peroxide production and decreases the amount of oxidative damage to mitochondrial DNA in synaptic and nonsynaptic brain mitochondria from female rats. ${ }^{40}$ Another effective means of preventing the mitochondrial spiral is by preventing the initial ROS production induced by toxic insults. One such target is the ROS production induced by calcium overload associated with disruption of mitochondrial calcium-buffering capabilities, as seen in many neurodegenerative diseases. ${ }^{41}$

With the loss of ovarian estrogen production after menopause, estrogen-containing hormone therapy (HT) might be expected to influence the risk of AD. ${ }^{19}$ A plethora of in vitro and in vivo studies have supported the neuroprotective role of estrogens and their impact on the neurotransmitter systems implicated in cognition. ${ }^{42}$ Recent hormonal replacement therapy (HRT) trials in nondemented postmenopausal women suggest a temporary positive effect (notably on verbal memory), and four meta-analyses converge to suggest a possible protective effect in relation to $\mathrm{AD}$ (reducing risk by $29-44 \%) .{ }^{43-46}$ However, data from the only large randomized controlled trial published to date, the Women's Health Initiative Memory Study, did not confirm these observations and have even suggested an increase in dementia risk for women using HRT compared to controls. ${ }^{47,48}$ Apart from methodological differences, one key shortcoming of this trial has probably been the focus on late-onset (postmenopausal) hormonal changes, i.e., at a time when the neurodegenerative process has already begun and without taking into account individual lifetime exposure to hormone variability. ${ }^{19}$ Multifactorial models based on an exhaustive view of all hormonal events throughout the reproductive life (rather than on a specific exposure to a given steroid) together with other risk factors (notably genetic risk factors related to estrogen receptor polymorphisms) should be explored to clarify the role of hormonal risk factors, or protective factors for cognitive dysfunction and dementia.

\section{Longevity in Females As an Example of Gender Effect on Human Life}

In the Western world, the average life span is 78.8 years for men and 84.1 years for women. ${ }^{49}$ Females also live longer than males in many other species, suggesting that this phenomenon cannot be attributed only to cultural/ anthropological habits, but rather may be a sign of specific biological uniqueness of both sexes, such as hormone production. As an example, testosterone decreases blood concentrations of high-density lipoprotein (HDL) and increases that of low-density lipoprotein (LDL), making males more prone to cardiovascular diseases. Conversely, estrogens reduce LDL and increase HDL, with beneficial effects on the cardiovascular system. ${ }^{50}$ On the other hand, the role played by oxidative damage in reducing lifespan is well known, because oxidative damage directly influences lifespan. In- terestingly, estrogens display antioxidant properties by upregulating the expression of the genes encoding antioxidant enzymes. Hence, they are responsible for the lower mitochondrial free-radical production observed in females as compared with males. ${ }^{51}$ If males and females suffer differing levels of oxidative insult, the resultant damage may therefore be sufficient to explain at least a part of sex-specific lifespan difference observed between the sexes. ${ }^{52}$

Because of the continuation of the decline in mortality at older ages in the Western world, an increasing number of individuals are becoming centenarians. ${ }^{53}$ Women are more likely to cross this threshold, and to such an extent that in lowmortality western countries, such as Italy, there are 5-7 women per man beyond this age. In addition to the role of estrogens in decreasing the levels of oxidative insults, 5 or 6 extra years might be ascribed to differences in social behavior between the sexes, because men take more risks. In fact, differences in mortality between men and women are not only a question of sex that refers to biological differences, but rather a question of "socially constructed sex"-a question of gender (i.e., the characteristics that a society or culture delineates as masculine or feminine). Behavioral and environmental factors clearly play a role in determining excess male mortality. Beyond a slight biological advantage for females, excess male mortality results from the emergency of typically male "man-made diseases." Work-related risk in industrial activity, alcoholism, smoking, and car accidents are the main factors contributing to excess male mortality. An aspect to be highlighted is that the attitude women generally have concerning their body, their health, and their lifestyle is very different from that of men. ${ }^{52}$ Furthermore, a positive association between genetic variants and longevity is often found only for males and rarely for both genders. This suggests that the longevity trait is more dependent on genetics in men than in women. So, a complex interaction of environmental, genetic, and historical factors likely plays an important role in determining the gender-specific probability of achieving longevity. ${ }^{54}$

Some years ago, we showed in our Sicilian population the presence of a female-specific gene-longevity association that paradoxically supports the role of sociocultural habits in female longevity. This concerns the HFE gene, localized on chromosome 6. Mutations in the class I-like major histocompatibility complex gene HFE are associated with hereditary hemochromatosis $(\mathrm{HH})$, a disorder caused by excessive iron uptake. Three common mutations have been found in this gene: C282Y, H63D, and S65C. In particular, the C282Y mutation (a cysteine-to-tyrosine mutation at amino acid 282) destroys its ability to make up a heterodimer with $\beta 2$ microglobulin. The defective protein fails to associate to the transferring receptor, and the complex cannot be transported to the surface of the duodenal crypt cells. As a consequence, in homozygous people, two to three times the normal amount of iron is absorbed from food by the intestine. We observed that this mutation is associated with longevity in Sicilian subjects. But analyzing data according to gender, we observed this mutation in old Sicilian women. Thus, the C282Y mutation may confer a selective advantage in terms of longevity in Sicilian women. Considering the historical and social context in which the generation of women under study lived, we have suggested that possession of iron-sparing alleles significantly increases the possibility for women to reach longevity. For instance, in Sicily, many pregnancies 
and an iron-poor diet, consisting mainly in grains, vegetables, and fruits, were still the rule for women born at the beginning of last century. In fact, meat was available for men but not for women; this clearly explains how genetic background also interacts with culture habits rather than sex. ${ }^{55-57}$

Further evidence for the role of cultural/anthropological habits (and therefore of gender) in achieving longevity is provided by epidemiological demography. In Italy, there is a north-to-south gradient in the female-to-male ratio in centenarians: 6 in the north, 3 in the center, and 2 in the south. In southern Italy, fewer women have become centenarians. To gain insight into the role of gender and environment, a demographic study has begun in Sicily. Demographers apply an indicator of mortality between the ages 80 and 100 to define the longevity of a population. Results obtained in Sicily highlight an area of longevity for men but not for women. The municipalities concerned do not include polluted areas and are small, with the lowest number of inhabitants. The reason for such a gradient is at present unknown. But it is likely that an important role might be played by the different rates of mortality between men and women, as well as social and anthropological differences. It has been reported that this ratio is higher in populations where life expectancy increases for economic and social reasons. ${ }^{58}$

Hence, a complex interaction of environmental, historical, and genetic factors, differently characterizing the various parts of Italy, likely plays an important role in determining the gender-specific probability of attaining longevity. In Sicily, longevity concerns men living in a small town, without pollution (different working conditions; different life style, i.e., smoking and alcohol abuse; Mediterranean diet). Why is there reduced longevity for women? Probably different social conditions and different educational levels might produce differential access to prevention or health facilities. Besides there is no longevity in polluted areas as expected, and longevity is represented in small municipalities. It is well established that old individuals with greater access to social support and family networks have better health and lower levels of mortality, particularly when adult daughters are present. ${ }^{52,59}$

In conclusion, in gender medicine it is important to consider the role played by hormones, customs, and educational levels in the different propensity of males and females to fall ill. These aspects must be taken into account in programming antiaging strategies. ${ }^{60,61}$

\section{Acknowledgments}

This work was supported by grants from the Ministry of Education, University and Research ex $60 \%$ to G. Candore and C. Caruso.

\section{References}

1. Angele MK, Frantz MC, Chaudry IH. Gender and sex hormones influence the response to trauma and sepsis: Potential therapeutic approaches. Clinics 2006;61:479-488.

2. Raju R, Bland KI, Chaudry IH. Estrogen: A novel therapeutic adjunct for the treatment of trauma-hemorrhage-induced immunological alterations. Mol Med 2008;14:213-221.

3. Qiao X, McConnell KR, Khalil RA. Sex steroids and vascular responses in hypertension and aging. Gend Med 2008; 5(Suppl A):S46-S64.
4. Chakrabarti S, Lekontseva O, Davidge ST. Estrogen is a modulator of vascular inflammation. IUBMB Life 2008;60: 376-382.

5. Członkowska A, Ciesielska A, Gromadzka G, KurkowskaJastrzebska I. Gender differences in neurological disease: role of estrogens and cytokines. Endocrine 2006;29:243-256.

6. Nilsson BO. Modulation of the inflammatory response by estrogens with focus on the endothelium and its interactions with leukocytes. Inflamm Res 2007;56:269-273.

7. Straub RH. The complex role of estrogens in inflammation. Endocr Rev 2007;28:521-574.

8. Candore G, Balistreri CR, Grimaldi MP, Vasto S, Listì F, Chiappelli M, Licastro F, Lio D, Caruso C. Age-related inflammatory diseases: Role of genetics and gender in the pathophysiology of Alzheimer's disease. Ann NY Acad Sci 2006;1089:472-486.

9. Di Bona D, Scapagnini G, Candore G, Castiglia L, ColonnaRomano G, Duro G, Iemolo F, Lio D, Pellicanò M, Scafidi V, Caruso C, Vasto S. Immune-inflammatory responses and oxidative stress in Alzheimer'disease: Therapeutic implications. Curr Pharm Des 2009 (in press).

10. Aronson MK, Ooi WL, Geva DL, Masur D, Blau A, Frishman W. Dementia. Age-dependent incidence, prevalence, and mortality in the old old. Arch Intern Med 1991;151:989-992.

11. Trojanowski JQ, Clark $\overline{\mathrm{CM}}$, Schmidt ML, Arnold SE, Lee VM. Strategies for improving the postmortem neuropathological diagnosis of Alzheimer's disease. Neurobiol Aging 1997;18:S75-S79.

12. Selkoe DJ Alzheimer's disease: Genes, proteins, and therapy. Physiol Rev 2001;81:741-766.

13. Vasto S, Candore G, Duro G, Lio D, Grimaldi MP, Caruso C. Alzheimer's disease and genetics of inflammation: A pharmacogenomic vision. Pharmacogenomics. 2007;8:1735-1745.

14. Mckhann G, Drachman D, Folstein M, Katzman R, Price D, Stadlan EM. Clinical diagnosis of Alzheimer's disease: Report of the NINCDS-ADRDA Work Group under the auspices of Department of Health And Human Services Task Force on Alzheimer's Disease. Neurology 1984;34:939-944.

15. Hy LX, Keller DM. Prevalence of AD among whites: A summary by levels of severity. Neurology 2000;55:198-204.

16. Vasto $S$, Candore $G$, Listì F, Balistreri CR, Colonna-Romano G, Malavolta M, Lio D, Nuzzo D, Mocchegiani E, Di Bona D, Caruso C.Inflammation, genes and zinc in Alzheimer's disease. Brain Res Rev 2008;58:96-105.

17. Gao S. Hendrie HC, Hall KS, Hui S. The relationships between age, sex, and the incidence of dementia and Alzheimer disease: A meta-analysis. Arch Gen Psychiatry 1998;55:809815.

18. Launer LJ, Andersen K, Dewey ME, Letenneur L, Ott A, Amaducci LA, Brayne C, Copeland JR, Dartigues JF, KraghSorensen P, Lobo A, Martinez-Lage JM, Stijnen T, Hofman A. Rates and risk factors for dementia and Alzheimer's disease: results from EURODEM pooled analyses. EURODEM Incidence Research Group and Work Groups. European Studies of Dementia. Neurology 1999;52:78-84.

19. Henderson VW. Estrogen-containing hormone therapy and Alzheimer's disease risk: Understanding discrepant inferences from observational and experimental research. $\mathrm{Neu}-$ roscience 2006;138:1031-1039.

20. Bedard P, Langelier P, Villeneuve A. Estrogens and the extrapyramidal system. Lancet 1977;2:1367-1368.

21. Cyr M, Calon F, Morissette M, Di Paolo T. Estrogenic modulation of brain activity: Implications for schizophrenia and Parkinson's disease. I Psychiatry Neurosci 2002;27:12-27. 
22. Currie LJ, Harrison MB, Trugman JM, Bennett JP, Wooten GF. Postmenopausal estrogen use affects risk for Parkinson disease. Arch Neurol 2004;61:886-888.

23. Paganini-Hill A, Henderson VW. Estrogen replacement therapy and risk of Alzheimer disease. Arch Intern Med 1996;156:2213-2217.

24. Henderson, VW. Estrogen replacement therapy for the prevention and treatment of Alzheimer's disease. CNS Drugs 1997;8:343-351.

25. Brinton RD. Impact of estrogen therapy on Alzheimer's: A fork in the road? CNS Drugs 2004;18:405-422.

26. Shughrue PJ, Lane MV, Merchenthaler I. Comparative distribution of estrogen receptor-alpha and -beta mRNA in the rat central nervous system. J Comp Neurol 1997;388:507525.

27. Toran-Allerand CD. Minireview: A plethora of estrogen receptors in the brain: Where will it end? Endocrinology 2004 145:1069-1074.

28. Henderson VW. Hormone Therapy and the Brain: A Clinical Perspective on the Role of Estrogen. Parthenon Publishing, New York, 2000.

29. Alkayed NJ, Murphy SJ, Traystman RJ, Hurn PD, Miller VM. Neuroprotective effects of female gonadal steroids in reproductively senescent female rats. Stroke 2000;31:161-168.

30. Goodman Y, Bruce AJ, Cheng B, Mattson MP. Estrogens attenuate and corticosterone exacerbates excitotoxicity, oxidative injury, and amyloid beta-peptide toxicity in hippocampal neurons. J Neurochem 1996;66:1836-1844.

31. Brinton RD, Tran J, Proffitt P, Montoya M. 17 beta-estradiol enhances the outgrowth and survival of neocortical neurons in culture. Neurochem Res 1997;22:1339-1351.

32. Foy MR, Baudry M, Diaz Brinton R, Thompson RF. Estrogen and hippocampal plasticity in rodent models. I Alzheimers Dis 2008;15:589-603.

33. Ohkura, T. et al. Estrogen increases cerebral and cerebellar blood flows in postmenopausal women. Menopause 1995;2: 13-18.

34. Bishop J, Simpkins JW. Estradiol enhances brain glucose uptake in ovariectomized rats. Brain Res Bull 1995;36:315320.

35. Petanceska SS, Nagy V, Frail D, Gandy S. Ovariectomy and 17 beta-estradiol modulate the levels of Alzheimer's amyloid beta peptides in brain. Neurology 2000;54:2212-2217.

36. Cushman M, Legault C, Barrett-Connor E, Stefanick ML, Kessler C, Judd HL, Sakkinen PA, Tracy RP. Effect of postmenopausal hormones on inflammation-sensitive proteins: The Postmenopausal Estrogen/Progestin Interventions (PEPI) Study. Circulation 1999;100:717-722.

37. Rosendaal FR, Helmerhorst FM, Vandenbroucke JP.et al. Female hormones and thrombosis. Arterioscler Thromb Vasc Biol 2002;22:201-210.

38. Beal MF Mitochondrial dysfunction in neurodegenerative diseases. Biochim Biophys Acta 1998;1366:211-223.

39. Nilsen J. Estradiol and neurodegenerative oxidative stress. Front Neuroendocrinol 2008;29:463-475.

40. Borrás C, Sastre J, García-Sala D, Lloret A, Pallardó FV, Viña J. Mitochondria from females exhibit higher antioxidant gene expression and lower oxidative damage than males. Free Radic Biol Med 2003;34:546-552.

41. Smith MA, Drew KL, Nunomura A, Takeda A, Hirai K, Zhu X, Atwood CS, Raina AK, Rottkamp CA, Sayre LM, Friedland RP, Perry G. Amyloid-beta, tau alterations and mitochondrial dysfunction in Alzheimer disease: the chickens or the eggs? Neurochem Int 2002;40:527-531.
42. Ryan J, Scali J, Carriere I, Ritchie K, Ancelin ML. Hormonal treatment, mild cognitive impairment and Alzheimer's disease. Int Psychogeriatr 2008;20:47-56.

43. Yaffe K, Sawaya G, Lieberburg I, Grady D. Estrogen therapy in postmenopausal women: Effects on cognitive function and dementia. JAMA 1998;279:688-695.

44. Hogervorst, E. Williams J, Budge M, Riedel W, Jolles J. The nature of the effect of female gonadal hormone replacement therapy on cognitive function in post-menopausal women: A meta-analysis. Neuroscience 2000;101:485-512.

45. LeBlanc ES, Janowsky J, Chan BK, Nelson HD.Hormone replacement therapy and cognition: Systematic review and meta-analysis. JAMA 2001;285:1489-1499.

46. Maki P, Hogervorst E. The menopause and HRT. HRT and cognitive decline. Best Pract Res Clin Endocrinol Metab 2003;17:105-122.

47. Shumaker SA, Legault C, Rapp SR, Thal L, Wallace RB, Ockene JK, Hendrix SL, Jones BN 3rd, Assaf AR, Jackson RD, Kotchen JM, Wassertheil-Smoller S, Wactawski-Wende J, WHIMS Investigators. Estrogen plus progestin and the incidence of dementia and mild cognitive impairment in postmenopausal women: The Women's Health Initiative Memory Study: a randomized controlled trial. JAMA 2003;289:2651-2662.

48. Shumaker SA, Legault C, Kuller L, Rapp SR, Thal L, Lane DS, Fillit H, Stefanick ML, Hendrix SL, Lewis CE, Masaki K, Coker LH, Women's Health Initiative Memory Study. Women's Health Initiative Memory Study. Conjugated equine estrogens and incidence of probable dementia and mild cognitive impairment in postmenopausal women: Women's Health Initiative Memory Study. JAMA 2004;291: 2947-2958.

49. www.istat.it

50. Viña J, Borrás C, Gambini J, Sastre J, Pallardó FV. Why females live longer than males: Control of longevity by sex hormones. Sci Aging Knowledge Environ 2005;2005:pe17.

51. May RC. Gender, immunity and the regulation of longevity. Bioessays 2007;29:795-802.

52. Candore G, Balistreri CR, Listì F, Grimaldi MP, Vasto $S$, Colonna-Romano G, Franceschi C, Lio D, Caselli G, Caruso C. Immunogenetics, gender, and longevity. Ann NY Acad Sci 2006;1089:516-537.

53. Franceschi C, Motta L, Motta M, Malaguarnera M, Capri M, Vasto S, Candore G, Caruso C; IMUSCE. The extreme longevity: The state of the art in Italy. Exp Gerontol 2008;43: 45-52.

54. Capri M, Salvioli S, Monti D, Caruso C, Candore G, Vasto S, Olivieri F, Marchegiani F, Sansoni P, Baggio G, Mari D, Passarino G, De Benedictis G, Franceschi C. Human longevity within an evolutionary perspective: The peculiar paradigm of a post-reproductive genetics. Exp Gerontol 2008;43:53-60.

55. Carru C, Pes GM, Deiana L, Baggio G, Franceschi C, Lio D, Balistreri CR, Candore G, Colonna-Romano G, Caruso C. Association between the HFE mutations and longevity: A study in Sardinian population. Mech Ageing Dev 2003;124: 529-532.

56. Lio D, Balistreri CR, Colonna-Romano G, Motta M, Franceschi C, Malaguarnera M, Candore G, Caruso C. Association between the MHC class I gene HFE polymorphisms and longevity: A study in Sicilian population. Genes Immun 2002;3:20-24.

57. Balistreri CR, Candore G, Almasio P, Di Marco V, ColonnaRomano G, Craxi A, Motta M, Piazza G, Malaguarnera M, Lio 
D, Caruso C. Analysis of hemochromatosis gene mutations in the Sicilian population: Implications for survival and longevity. Arch Gerontol Geriatr Suppl 2002;8:35-42.

58. Rigby JE, Dorling D. Mortality in relation to sex in the affluent world. I Epidemiol Community Health 2007;61: 159-164.

59. Bürkle A, Caselli G, Franceschi C, Mariani E, Sansoni P, Santoni A, Vecchio G, Witkowski JM, Caruso C. Pathophysiology of ageing, longevity and age related diseases. Immun Ageing 2007;4:4.

60. Jirillo E, Candore G, Magrone T, Caruso C. A scientific approach to ti-ageing therapies: State of the art. Curr Pharm Des. 2008;14:2637-2642.
61. de Grey AD. Consolidating the mission to defeat aging: A big step forward. Rejuvenation Res 2008;11:1061-1063.

Address correspondence to: Giuseppina Candore Dipartimento di Biopatologia e Metodologie Biomediche Università di Palermo

Corso Tukory 211 90134 Palermo Italy

E-mail: gcandore@unipa.it 